\title{
COMMENTARY
}

\section{Is enough oxygen too much?}

\author{
Paul T Schumacker* \\ See related viewpoint by Martin et al., http://ccforum.com/content/14/4/315
}

\begin{abstract}
Human cells require $\mathrm{O}_{2}$ for their energy supply, and critical illness can threaten the efficient delivery of $\mathrm{O}_{2}$ in accordance with tissue metabolic needs. In the accompanying article, Martin and colleagues point out that hypoxia is a normal and welltolerated stress during embryonic development. A better understanding of how fetal cells survive these conditions and how adult cells adapt to high altitude exposure may provide insight into how these mechanisms might be engaged in the treatment of hypoxemic patients. They suggest that'permissive hypoxia' represents a therapeutic possibility. But before we turn down the inspired $\mathrm{O}_{2}$ levels we should consider the broader effects of hypoxia on tissue repair in critical illness.
\end{abstract}

Intensivists direct much effort toward maintaining tissue oxygenation in critically ill patients. While the consequences of oxygen deprivation are well known, we also know that excessive oxygenation creates new problems because hyperoxia exacerbates lung injury. So like many things in life, 'too much' is not the solution to 'not enough.

Assessments of tissue oxygenation have taught us that 'normoxia' differs among organs, and that tissue oxygenation can decrease when the environment or activity levels change. For example, lung alveolar cells normally reside under $14 \% \mathrm{O}_{2}$, while oxygenation in intestinal epithelium can be less than $2 \%$. Severe exercise decreases myocardial oxygenation from $4 \%$ to less than $1 \% \mathrm{O}_{2}$, while high altitude induces systemic hypoxemia. During embryonic development, systemic oxygenation in the fetus is severely hypoxic by comparison to the adult.

*Correspondence: p-schumacker@northwestern.edu

Division of Neonatology, Department of Pediatrics, Northwestern University Feinberg School of Medicine, 310 E. Superior St, Morton Bldg 4-685, Chicago, IL 60611, USA
While severe hypoxia can threaten survival at any stage of life, it is interesting that our cells often experience significant hypoxia without sustaining injury. Moreover, we have learned that both cells and organisms quickly acclimate to lower oxygen environments. This is evidenced by altitude-acclimated climbers near the summit of Mt Everest who were alert with arterial $\mathrm{PO}_{2}$ less than $25 \mathrm{mmHg}$ ! A similar level in a critically ill patient would be ominous. So why is hypoxia tolerated well in some circumstances but not in others?

In this issue of Critical Care, Dr Martin and colleagues consider the effects of hypoxia on physiology, and they review mechanisms allowing cells and organisms to tolerate oxygen deprivation without sustaining injury [1]. One mechanism involves the up-regulation of protective genes by hypoxia-inducible factor (HIF) transcription factors [2]. The cadre of genes controlled by HIF varies among cell types, but generally includes the expression of glycolytic enzymes, glucose transporters, vascular growth factors, and genes regulating vascular tone and systemic oxygen transport [3]. HIF also contributes to the downregulation of mitochondrial respiration, which lessens tissue need for oxygen. Loss of HIF is lethal during embryonic development, largely because hypoxia acts as a morphogen controlling migration and differentiation of cells in the embryo and placenta [4].

Other systems engaged by hypoxia include AMPdependent protein kinase (AMPK), which responds to increases in cellular [AMP] and is also activated by hypoxia. AMPK preserves energy substrate supply by upregulating glycolysis and fatty acid oxidation [5]. AMPK also regulates other biological processes.

Interestingly, $\mathrm{O}_{2}$ acts as a signal in triggering the activation of both HIF and AMPK during hypoxia by releasing low levels of reactive oxygen species (ROS) from the electron transport chain [6]. These ROS migrate to the inter-membrane space where they can escape to the cytosol and trigger the activation of HIF and AMPK [7]. Thus, $\mathrm{O}_{2}$ acts in a paradoxical manner as a signaling molecule activating protective mechanisms during hypoxia.

Martin and colleagues raise the provocative concept of 'permissive hypoxia' in critical illness. To be sure, the degree to which hypoxemia should be corrected is incompletely understood. A reduction in cellular energy 
demand during hypoxia, a form of adaptive hibernation, could lessen the consequences of oxygen deprivation. But before we reach for the $\mathrm{FIO}_{2}$ control on the ventilator, we should consider other arguments. First, organ failure is essentially a situation where cells fail to perform their normal tissue function. In heart failure, cardiomyocytes are alive yet they fail to contract normally. In hypoxic tissues, adaptive responses might foster survival, but the consequences for organ function can be catastrophic. For example, in hypoxic lungs ROS signals activate AMPK, which triggers internalization of the epithelial $\mathrm{Na}, \mathrm{K}-$ ATPase, an enzyme essential for alveolar edema reabsorption [8]. Hence, responses triggered by hypoxia may not optimize tissue repair and survival in the critically ill. Finally, intensivists need to know whether all cells in a tissue are oxygenated. Microvascular heterogeneity in the patient can create local hypoxic areas within excessively perfused regions. At the tissue level perfusion seems adequate, yet some cells are struggling in hypoxic islands'. A parallel situation occurs in solid tumors, where local cellular anoxia occurs despite high blood flows and excessive (albeit abnormally structured) capillary density [9]. So high overall blood flow does not guarantee uniform oxygenation.

In summary, hypoxia triggers protective responses, but not all of these are adaptive at the tissue level. A better understanding of the heterogeneity of microvascular oxygen supply in the critically ill patient would help us begin to understand the situation before we turn down the oxygen.

\section{Abbreviations}

AMPK = AMP-dependent protein kinase; $\mathrm{HIF}=$ hypoxia-inducible factor; $\mathrm{ROS}=$ reactive oxygen species.
Competing interests

The author declares that he has no competing interests.

\section{Acknowledgments}

Supported by HL35440, HL079650, and RR025355.

Published: 24 August 2010

\section{References}

1. Martin DS, Khosravi M, Grocott MPW, Mythen MM: Concepts in hypoxia reborn. Crit Care 2010, 14:315.

2. Schumacker PT: Hypoxia-inducible factor-1 (HIF-1). Crit Care Med 2005, 33:S423-S425.

3. Semenza GL: HIF-1, 02 , and the 3 PHDs: How animal cells signal hypoxia to the nucleus. Cell 2001, 107:1-3.

4. Maltepe E, Schmidt JV, Baunoch D, Bradfield CA, Simon MC: Abnormal angiogenesis and responses to glucose and oxygen deprivation in mice lacking the protein ARNT. Nature 1997, 386:403-407.

5. Evans AM, Hardie DG, Galione A, Peers C, Kumar P, Wyatt CN: AMP-activated protein kinase couples mitochondrial inhibition by hypoxia to cell-specific $\mathrm{Ca} 2+$ signalling mechanisms in oxygen-sensing cells. Novartis Found Symp 2006, 272:234-252

6. Guzy RD, Hoyos B, Robin E, Chen H, Liu L, Mansfield KD, Simon MC, Hammerling U, Schumacker PT: Mitochondrial complex III is required for hypoxia-induced ROS production and cellular oxygen sensing. Cell Metab 2005, 1:401-408.

7. Chandel NS, Maltepe E, Goldwasser E, Mathieu CE, Simon MC, Schumacker PT: Mitochondrial reactive oxygen species trigger hypoxia-induced transcription. Proc Natl Acad Sci USA 1998, 95:11715-11720.

8. Gusarova GA, Dada LA, Kelly AM, Brodie C, Witters LA, Chandel NS, Sznajder Jl: Alpha1-AMP-activated protein kinase regulates hypoxia-induced $\mathrm{Na}$,K-ATPase endocytosis via direct phosphorylation of protein kinase $\mathrm{C}$ zeta. Mol Cell Biol 2009, 29:3455-3464.

9. Dewhirst MW, Tso CY, Oliver R, Gustafson CS, Secomb TW, Gross JF: Morphologic and hemodynamic comparison of tumor and healing normal tissue microvasculature. Int J Radiat Oncol Biol Phys 1989, 17:91-99.

doi:10.1186/cc9201

Cite this article as: Schumacker PT: Is enough oxygen too much? Critical Care 2010, 14:191. 